\title{
The Effect of Perceived Risk on Intention to Use Online Banking
}

\author{
Reepu $^{1, *}$, Rakhi Arora ${ }^{2}$ \\ ${ }^{1}$ Research Scholar, Department of Management, Chandigarh University, Punjab, India \\ ${ }^{2}$ Assistant Professor, Department of Management, Chandigarh University, Punjab, India
}

Received September 21, 2021; Revised November 13, 2021; Accepted December 23, 2021

\section{Cite This Paper in the following Citation Styles}

(a): [1] Reepu, Rakhi Arora, "The Effect of Perceived Risk on Intention to Use Online Banking," Universal Journal of Accounting and Finance, Vol. 10, No. 1, pp. 62-71, 2022. DOI: 10.13189/ujaf.2022.100107.

(b): Reepu, Rakhi Arora (2022). The Effect of Perceived Risk on Intention to Use Online Banking. Universal Journal of Accounting and Finance, 10(1), 62-71. DOI: 10.13189/ujaf.2022.100107.

Copyright $\odot 2022$ by authors, all rights reserved. Authors agree that this article remains permanently open access under the terms of the Creative Commons Attribution License 4.0 International License

\begin{abstract}
Online banking is a major service for the contemporary banking sector's expansion plan. Numerous researchers have contributed to the research paradigm the positive aspects of online banking. Consumers sense the interconnectivity due to its presence online. Nonetheless, this service was not extensively utilized due to consumers' remaining afraid of the danger of online transactions. Users fear to use such services online due to the prevalence of different kinds of risks. Thus, the detailed and distinctive risk job in risk awareness for the banking industry is an important and useful task. The influence of perceived risk in online banking use is investigated in this research. As it has been regarded for the majority of times, perceived risk serves as one of the major barriers towards usage of such kind of services. The paper has set out the varied categorical risks like privacy, social risk etc. which influences the usage or intention towards usage of such online banking services. The research model is envisaged on the basis of different theories of information technology acceptance. Questionnaire method was employed to obtain responses specifically from female users of online banking. Data collected were analyzed through Structural Equation Modelling (SEM). Results have been analyzed well. The findings of SEM show risk elements "privacy risk, security risk, social risk, time risk, and financial-performance risk" in perceived risk, which has a negative impact on desire to utilize online banking. Research findings may assist in suggesting ways to improve safety and mitigate online banking risks prevalent among users.
\end{abstract}

Keywords Perceived Risk, Online Banking, Users

\section{Introduction}

The term internet banking is the supply of information and services provided by the bank with the use of a computer to its customers. More sophisticated services provide customers the chance to check their accounts, carry out transactions and even purchase online products via the net. Internet banking provides banks with more facilities and customers may obtain services. This means that Internet banking users are interconnected via the Internet, while mobile banking users are interconnected by wireless devices.

Many of the characteristics for practices and the non-use of Internet banking services may be mentioned in underdeveloped nations. Ezeoha A.E. [17] is arguing in Nigeria that internet services are so lenient than those of industrialized nations and part of the continent of Africa. Nigeria is classified as a new invention for online banking services. Therefore, a sensitive subject in the Nigeria banking industry may be enhanced for future purposes for quality and quantity. Although online banking has several advantages, such as faster transactions, speed, and subordinate oversight duties, significant numbers of customers still do not embrace Internet banking.

Featherman \& Pavlou [18] has indicated that perceived danger is proposed as a barrier to online banking adoption by customers. When setting up Internet banking, danger may either be observed through assaults of the system and exchange of information or by untruthful and poor verification via unlawful access to the account. Thus, many problems from economic loss to secrecy may be addressed through perceived risk. 
Like online purchases, internet banking adoption is traditionally more complex since it ensures that users and internet banking services have a long-term relationship. According to Byrne B. M [9], a significant measure for customers, as they contemplate entering a commercial connection with reserved, unknown Internet banking services, has been taken into account in many studies' views on the dangers of embracing Internet banking. Perceived risk changeable a single idea has previously been shown to mimic the real characteristics of perceived risk and explain why clients struggle against financial services. Numerous research projects, however, have previously taken into account the factors which affect IT adoption or the internet in the past period of Heijden; the partly experiential work by Taylor et al. [45] captures elements or positive characteristics of Internet banking in others to assist shape a tactical agenda.

Several studies have previously shown that the use of internet services was hampered by issues of secrecy such as Westin [49]; Ackerman, $M$ et al. [1] etc. Users would want to determine what kind of information is being gathered and for what reasons, how long, and what purpose the file is being processed. The research emphasized two ideas of a reasonable act technology acceptance model to offer a sound theoretical basis for checking the adoption of internet banking services (Technology Acceptance Model) The planned behavior hypothesis Davis, F. et al [13] Azjen, I. [2] posits five risks: risk of safety, financial risk, social risk, risk of time or convenience and risk of performance. All of these dangers are linked to online banking. The Internet banking issue as mentioned Haque et al. [24], Durkin et al [16] have claimed that the acceptance and use by majority of the banking customers of Online banking services remains ineffective, notwithstanding of significant internet banking savings by many monetary institutions worldwide. The outcome is because of the perceived danger associated with the use of online banking services.

\subsection{Perceived Risk}

Since the 1960s, perceived risk was employed to explain client behavior (Forsythe S.M. and Shi B) [20]. The perceived risk is a feeling of loss in Bauer, R.A. [8], Dowling G.R. [15] defined risks as "a scenario in which both alternative outcomes and their chance of occurrence are a previous knowledge of the decision-maker."

The risk perception, in conjunction with risk inclination, "is one of the drivers of risk behavior, according to Sitkin S.B. and Pablo A.L. [43]". In the context of internet buying, Forsythe S.M. and Shi B [20] defined perceived risk in the context of a "on-line shopping member's subjectively decided anticipation of loss."

In the online transaction environment, some kinds of hazards are significant. "Online-based transactions, product performance hazards, financial risks, time and mental health risks and other risk kinds, both for internet and internet buyers, predominate (Forsythe S.M. and Shi B) [20]. The scientists also discovered that the browsers saw much greater financial, time and psychological hazards than those of heavy and moderate consumers. Featherman \& Pavlou [18] showed that when participants perceive less behavioral and contextual uncertainty", they may see greater control over the usage of online transaction. Therefore, when the perceived risk is minimal (as opposed to large), consumers may contemplate transacting using online platforms. Uncertainties about the prospective or current connection that needs website confidence are a consequence of perceived risk, as reported by Hampton-Sosa W and Koufaris M [23].

Yousafzai S.Y. et al. [51] has researched several models aimed at showing that Internet banking consumers embrace technology. The planned conduct theory (Ajzen, I., [3]), "which extends the reasoned action theory (Fishbein, M., \& Ajzen, I., [19]), include perceived behavioral control as part of the models. The perceived behavioral control, according to Ajzen, I., [3], comes from control beliefs that deal either with accessible or unavailable resources and opportunities and the expectation of barriers to targeting", for example, the adoption of Internet banking. The technology acceptance model proposed by Davis, F et al. [14] was another paradigm that was considered, "This model shows the perceived utility and usability of buildings. Both are closely linked to the results and the technology's operationalization".

Theory of planned behavior as well as the model of technological acceptance is implicated in the risk perception, particularly in terms of the trust that a technology is beneficial to the work of a user.

Overall, the perceived risk affects adoption of internet banking, Tan, M., \& Teo, T. S., [44], Maditinos et al [30], have had significant and bad effects on consumers' acceptance by online banking of two different dimensions of perceived risk: performance risk (e.g. problems of connection, loss of data, etc.) and safety risk (e.g. data transaction attacks). Barros L., et al., [7] connected the perceived danger of debt and shown that the higher the perceived risk of debt, the lower the risk of debt.

\subsection{Performance Risk}

The customer's evaluation of risk performance takes their knowledge and rationale in a certain subject field into consideration.

In the absence of individual contacts, the customer cannot adequately evaluate the item's characteristics and reduce safety in the form of asymmetry in Internet banking data, the likelihood of failure and not execution, as anticipated and advertised, and thus the desired benefit deteriorated. A method of delivering advantages to consumers may also be called a fear of loss if a variety, product or dealer does not achieve the same thing as planned. The risk of performance involves losses from online banking platforms' deficiencies or shortcomings. Sometimes customers are worried about system server failure or website closure since circumstances may lead to 
unexpected fatalities.

\subsection{Social Risk}

Social risk is the concern about the probability that a particular thing may lead to negative consideration and response. The social well-being of the customer who uses online banking services may be affected by the good or bad perception of individuals, family or companions in Internet banking management. People who perceive social connections are more unwilling to create an elevating attitude or positive approach to Internet banking consider the numerous methods utilized to get their features. The absence of human collaboration may prevent the utilization of innovation-oriented infrastructures.

Social risk refers also to an imminent loss of rank in the community gathering, as an effect of adopting items and administrative systems that seem unfashionable. The choice of using online banking may result in condemning a family or group. It is conceivable that the social stand-up in the field of online banking may be enhanced or diminished. These people may have a disadvantageous or favorable view of online banking. In other words, the views of its adopters that Internet banking does not embrace may have bad or good consequences.

\subsection{Time Risk}

There is a combination of wasted time and effort in the purchase of all items and services. When more time is necessary to research how to get to a particular administration, there is an increase in risk perception. Customers are told that they are at risk when currency transfers are not understandable in due course and mistakes occur within the transaction period that reverts to period loss. Discomfort and time may be a result of losses due to a delay in payment or directing effort (discovery suitable services and hyperlinks). It could not be feasible to download two main reasons of discomforts to online banking experience which could be seen as a time risk involving a confusing website and pages that are so sluggish. The time involved in the information about perfuming online banking websites may be linked, and time is wasted when consumers make a poor decision by spending time exploring and completing their purchases, learning to use the product only to replace it if the expectations are not met.

\subsection{Financial Risk}

Risk also includes monetary risk, which in the processes of online buying or purchasing is the probability of economic loss. According to Ajzen, I., [2]; Aladwani A.M., [4] the loss of money as a result of the acquisition of goods and facilities is in another manner around FR. In the risk assessment of Internet banking customers, IT gaps and the consequent losses in misleading client accounts are primarily cultivated. It is also known as the possibility of financial loss due to transaction errors or theft of bank account. For example, reliable merchants carry inadequate goods or even fail to provide goods to customers. People sometimes pay money to revise difficult things. Again, while dealing with the Internet, Master Card information may be deleted.

\subsection{Security Risk}

Different studies have shown that security risks are fascinating to customers with regard to security issues via the highest Internet banking tests. This danger creates security risks when consumers are ready to transfer money from their own accounts or reliable economic information to others who are deprived of their permission. The key impediment to using online banking is security risk. Improved safety in the defense of private information may increase the degree to which online banking is made available as has been suggested. Risk to security and privacy is classified as a potential default owing to fraud or a hacker that negotiates security for a user of an online bank. Phishing is a different original misbehavior, where Phishers try to trickle get sensitive information, such as user names, passwords and subtle items from MasterCard, in an automated message as a reliable object.

\subsection{Effect of Perceived Risk on Internet Banking Intention}

Studies have shown that the risk is regarded as a key element and its link to online banking. Past research has shown that the danger associated with deaths is more noticeable than in usual circumstances in the Internet banking exchange.

The concept of perceived risk first came from Bauer, R.A. [8]. He identified the risks as regards instability and results related to the actions of a customer. Consumer researchers, for example, describe risk as a customer's perception of hesitation and the unfavorable results of buying an item (or facility). Risk perceived with the associated negative effect increased vulnerability and size.

Risks were seen as multidimensional theory in a number of research. Prior effort has been shown to include different types of risk, including risk of performance, social risk, time risk, monetary risk and security risk, which include perceived danger. Zimund confirmed the importance of the risk associated with the opportunity cost of a purchasing option. It became known that customers needed more facts to decide on a riskier alternative.

\section{Literature Review}

Halvadia, Nirav \& Patel, Vipul [22] analyzed how the attitude to Internet banking use of online trust and perceived risk affects. This research examined the role of 
online trust in the context of Internet banking and the perceived risk. Psychometric characteristics had been evaluated using Cronbach alpha and the first order confirmatory factor analysis for each perceived risk of online banking (CFA). The second order CFA was then conducted to assess each risk facet's relative significance. Additional structural equation modeling using AMOS software was conducted to investigate the effect on the attitude to internet banking of perceived danger and online trust. The sample included 200 adopters and no adopters of online banking. The following aspects were identified: security risk, financial risk, privacy risk, time-loss risk and performance risk, and it was also discovered in the online banking adoption that respondents did not see any social danger. The findings indicated that the perceived risk negatively affects the attitude to Internet banking adoption whereas online confidence has a favorable influence. Practical implementation: Indian banking sector requires a publicity campaign to build online confidence and minimize risk associated with internet banking. For bank managers, it is essential to grasp how to build internet banking online trust. Financial risk and time loss risk are the main influencing factors for online bank adoption. Bank managers should convey that Internet banking is financially secure and saves your time with their target audience. Structure Equation Modeling: Internet Banking, online trust, perceived risk, internet banking behavior, first orders CFA, second orders CFA.

In order to identify those variables affecting the desire to use mobile bank services in Saudi Arabia, the study conducted by Al-Jabri, I. M. [6] aimed to build and evaluate a research model. The research used the Partial Least Squares (PLS) to experimentally evaluate the model using a paper-based survey of 253 respondents. With 66.7 percent of the variation in mobile banking intention, the findings provide significant support for the validity of the suggested model. The findings also showed that compatibility was the most intentional factor, whereas perceived danger was a barrier to mobile banking. The connection between trust and perceived risk was significantly bad and suggested that trust may reduce the risk barrier that could affect mobile banking intention. Unlike prior study, there was no substantial impact on mobile banking's aim on perceived utility and perceived ease of use. The consequences of the results were examined and recommendations were given for further study. Kassim N.M. et al. [25] identified risk variables influencing the intention of continued use of Internet banking in Malaysia. Personal Internet banking customers in Peninsular Malaysia were the main participants. Data have been gathered via a self-administered questionnaire using the DOPU technology. Through this approach, the questionnaires are disseminated to the various bank managers who are ready to distribute. As requested, a total of 413 interrogators were completed. For data analysis and hypothesis testing, the SPSS statistical analysis software and partial minimum squares have been employed. The findings indicated that social risk, danger of time loss, cost of opportunity and perceived utility are important variables that affect your willingness to continue to utilize Internet banking. Having the Internet banking system in Malaysia will be influenced by a major aspect. Other postulated connections are not important. A total of 413 interviewees could not reflect the population as a whole. In addition, interlocutor profiles were private and the management of the institutions was not revealed. Therefore, for each bank, it was not known the entire number of internet banking clients. The results of this research should be very useful for Internet banking service providers. A knowledge of the variables indicated in the research enables internet banking providers to improve services in the most efficient and effective manner to possibly grow bank business in the long term.

Namahoot, K.S. et al. [32] examined the relationships between five dimensions of the quality of services with overall compartmental intent to use Internet banking in Thailand and the indirect effect between service quality and compartmental intentions to use Internet banking as mediation variables using perceived risk and trust. The 505 respondents for this research were selected using a multi-stage sampling method. The participants were chosen on the basis of their experiences in Thailand with Internet banking. The data from participants were examined using a modeling method using structural equations. The findings demonstrate that the quality of service, risk perception and confidence affect the behavior of online banking. The main objective of the research is to determine if perceived risks and trust were mediator variables or the usage of online banking between service quality and behaviors. When building a system in line with prospective user requirements and lifestyles, and CEOs establish strategies and appropriate policies in order to gain the competitive advantage, the research should be helpful to developers in internet banking.

\section{Research Conceptual Framework}

The factors of this research include perceived risk, risk to performance, the social risk, time risk, financial risk and security risks. The following framework describes the connection between the perceived dangers of using the web banking and the intention to utilize the web banking. This study believes that the increase in risk that prospective consumers perceive reduces the intention to use the services of Internet banking. Thus, the link between perceived risk and desire to utilize Internet Banking Services is predicted to be positive.

\subsection{Research Model and Hypotheses}

"This study is based on theories of the IT adopted by Chen C.S. [10], Littler \& Melanthiou [29], Aldás-Manzano et al., [5], Martins et al. [31], Khan et al. [26], Pikkarainen et al. [39], TPB, UTAUT and other theories of IT adoption, perceived risk theory, such Bauer, R.A. [8], Featherman \& 
Pavlou [18], Park et al [36]." This research provides an assessment of significant perceived risk effects on India's desire to utilize internet banking, the corresponding literature and the following assumptions.

\section{(1) Perceived Risk}

- According to Littler \& Melanthiou [29] Risk perceived in decision-making about acquiring new technology/services (RIS) is important. Many writers demonstrate the kind of danger. "Some kinds of hazards - privacy risk, safety risk, social risk, financial risk, time risk and performance risk, are said to exist". The perceived risk is therefore a second order, represented and deconstructed in its first order as a composite variable.

- Privacy Risk (PRR) is linked to the possibility of exposure for direct marketers to personal information from customers, whether inside or outside the business. In the context of internet banking, when the service is used by hackers or by banks to exchange client documents with outsiders for another reason, customers may screen for their identity. Chen C.S. [10] and Yang et al., [50] research have shown that the danger of privacy is a significant issue for customers to decide whether to utilize it.

- Security risk (SER) may be the most damaging drawback of services with the external infringement effect of the money taken Accounts and personal details on financial inspections. With regard to online banking, the danger of security arises when banks are entered. Fraud or hackers may occur. Earlier studies such as Chen C.S. [10], Aldás-Manzano et al., [5] and Yang et al., [50] etc. have shown that security risk has effects on Internet banking adoption.

- Social risk (SOR) the potential for unfavorable reactions from the consumer social webs has to do with the social risk (SOR). Online banking involves social risk as a result of a lack of contact or engagement with the employees of the bank. The research conducted by Chen C.S. [10], Featherman \& Pavlou [18], and Martins et al. [31] have shown the detrimental effect of social risk.

- Performance risk (PER) relates to concerns about the performance of services or goods not as anticipated. The risk of performance in the online banking environment refers to harmful damage caused by the bank failure or weakness. In research conducted by Featherman \& Pavlou [18], Litter \& Melathiou, Martins et al. [31] and Roy S.K. et al., [41] and others, performance risk was addressed as an impediment to on-line banking intention.

- Financial risk (FIR) "The possible budgetary expenditure not only linked to the original purchase price but also the future product maintenance cost has to do with the financial risk (FIR) or economic risk. Financial risk may be seen as the investment cost of computers or of the Internet in the context of online banking. The financial risk is a major hazard in the online adoption of banking, according to Chen C.S. [10], Featherman \& Pavlou [18], Martins et al. [31], Roy S.K. et al., [41]"

- Time Risk (TIR) is related to the impression that the service is used and adoption is going to take too long. Time risk refers to the duration of navigation time, the learning of how to utilize online banking or the repairing of erroneous transactions inside an online banking environment. The study findings of Martins et al. [31], Featherman \& Pavlou [18] and Yang et al., [50], proved that the usage of internet banking purpose is prejudiced by time risks.

Online banking speculated that perceived risks are comprised of the aspects termed "privacy risk, security risk, social risk, financial risk, time risks and performance risk": Chen C.S [10], Featherman \& Pavlou [18], Littler \& Melanthiou [29], Martins et al. [31]. Therefore, we assume:

H1: A second component to the perceived risk includes six risks: risk to privacy, danger to security, social risk, financial risk, time risk and risk to performance.

H1a: Privacy risk has positively related to perceived risk.

H1b: Security risk has positively related to perceived risk.

H1c: Social risk has positively related to perceived risk.

H1d: Performance risk positively related to perceived risk.

H1e: Financial risk has positively related to perceived risk.

H1f: Time risk has positively related to perceived risk.

\section{(2) Intention to Use}

The intention to use it (ITU), as consumers unconsciously and intentionally perceive risks during the conjecture or adoption of services or products, is considered essential to include measurements of a perceived danger of technology adoption. The combination of loss probability - considered to enhance the danger - has been discovered by Featherman \& Pavlou [18] to prevent the usage of internet banking. The perceived negative risk impacts on intent according to Martins et al. [31] We thus believe that:

\section{H2: "Perceived risk negative effect on intention to use."}

\subsection{Research Methods}

The data will be reviewed in a study utilizing all indications of research design skills for model accreditation and research hypotheses. An investigation was carried out using simple sampling to gather study data. The surveys have been delivered through e-mail and Google documents to respondents wishing to use and employ online banking activities. 238 responses of female were collected and 226 might be utilized (12 invalid respondents). All variables evaluated using a 5 point Likert 
scale: (1) - a strong disagreement; (2) - a disagreement; (3) a strong disagreement; (4) a strong disagreement; responses were tested with IBM software including AMOS and SPSS have been investigated using SEM (structural equation modeling).

\section{Research Results}

\section{A. Sample Statistics}

The age group: $18-22$ years is 61.7 percent plurality; 23-29 years old are 19.2 percent comparatively lower; other age groups are relatively low. Gender: with 100\% female, there is no substantial difference. Education: in terms of graduates of universities, graduates of various degree programs and postgraduate degrees, the highest of which is about $78.2 \%$, "followed by university students of $13.7 \%, 8.1 \%$, respectively. Revenue: $42-10 \%$ of the Indian Rupee 5 million, Indian Rupee 5-10 million, Indian Rupee 11-20 million and Indian Rupee 11.2\%. And lower amounts of the other categories. Indian Rupee 5-10 million. Job: about $45.0 \%$ of students, approximately $24.7 \%$ of employees, $9.3 \%$ of managers at a lower level, and a smaller proportion of other employers are employed. Use Experience: $38.1 \%$ is 1 to 5 years, $23.4 \%$ is 1 to 5 years and
$17.6 \%$ is less than 1 to 5 years. Bank account: accounts with commercial banks (SBI, HDFC etc.) constitute $64.1 \%$, $38.6 \%$, and external banks (HSBC, Citibank, etc.) 6.2\%".

\section{B. Factor analysis exploratory and confirmatory}

\section{1) Exploratory factor}

"The first EFRE (exploratory factor analysis) with EFA factor loading $<0.50$ [14] after removing six items - SOR4, PER4, FIR3, FIR5 and TIR2 of Social Risk (SOR) and TIR2, Time risk (TIR), Performance Risk (PER) and Financial Risk (FIR)". The second EFA, including 22 items, sorted according to the model, by each component. It still contains one element - PER3 of the primary order dimension of PER is combined into the first order element Security Risk (SER). Four articles - PER1 and PER2 are coupled with FIR1 and FIR2 of financial risk (FIR), and this articulation is called "Financial risk performance risk" (F-PR). "The F-PR component implies that the financial risk interaction with the perceived risk performance risk. All indicators range from 0.580 to $0.870(>0.5)$ to EFA Factor Loading. The CR of the dimensions is also 0.691 to 0.880 (> 0.6) Composite reliability (CR) (Table I). H1d, $\mathrm{H} 1 \mathrm{e}$ and $\mathrm{H} 1$ are thus repurposed with the H1d-e and H1' hypotheses":

Table 1. Results of factor analysis

\begin{tabular}{|c|c|c|c|c|}
\hline \multirow{2}{*}{\multicolumn{3}{|c|}{ Talent/Indicators }} & \multicolumn{2}{|c|}{ Factorloading } \\
\hline & & & $E F A$ & $C F A$ \\
\hline \multicolumn{5}{|c|}{$" \mathrm{CR}=0.849 ; \mathrm{AVE}=0.613 "$} \\
\hline \multirow{4}{*}{$P R R$} & PRR4 & The bank may share user information to other parties & 0.795 & 0.867 \\
\hline & PRR2 & Payment information for users on OB may be exposed & 0.760 & 0.782 \\
\hline & $\mathrm{PRR}_{3}$ & OB user account may be taken by hackers & 0.741 & 0.770 \\
\hline & PRR1 & Others may use user information unlawfully & 0.652 & 0.670 \\
\hline \multirow{5}{*}{ SER } & \multicolumn{4}{|c|}{ "CR $=0.776 ; \mathrm{AVE}=0.516 "$} \\
\hline & SER1 & The Internet is not financially secure & 0.737 & 0.813 \\
\hline & SER2 & Bank systems may readily be used by hackers & 0.731 & 0.715 \\
\hline & SER3 & Financial information and user information are not secure & 0.723 & 0.612 \\
\hline & PER3 & OB cannot function as a publicity & 0.580 & Eliminated \\
\hline \multirow{4}{*}{$S O R$} & \multicolumn{4}{|c|}{$" \mathrm{CR}=0.691 ; \mathrm{AVE}=0.504 "$} \\
\hline & $\mathrm{SOR}_{2}$ & People surrounding OB are not appreciated & 0.755 & 0.794 \\
\hline & SOR1 & Other persons affect the usage of $\mathrm{OB}$ adversely & 0.693 & 0.678 \\
\hline & $\mathrm{SOR}_{3}$ & Think badly of the user who is incorrect & 0.676 & 0.647 \\
\hline \multirow{5}{*}{$F-P R$} & \multicolumn{4}{|c|}{ "CR=0.700;AVE=0.502" } \\
\hline & PER1 & Bank systems may decrease OB's performance & 0.741 & 0.737 \\
\hline & FIR2 & Money danger may arise if sloppy information is entered & 0.674 & 0.676 \\
\hline & PER2 & OB may be a failure in the payment procedure & 0.625 & Eliminated \\
\hline & FIR1 & Money risk may arise if third party unlawful conduct & 0.607 & Eliminated \\
\hline \multirow{4}{*}{$T I R$} & \multicolumn{4}{|c|}{ “CR $=0.695 ; \mathrm{AVE}=0.506 ”$} \\
\hline & TIR3 & It takes a long time to register/learn $\mathrm{OB}$ & 0.780 & 0.746 \\
\hline & TIR4 & It takes a long time to repair $\mathrm{OB}$ problems & 0.774 & 0.723 \\
\hline & TIR1 & It takes a long time to trade online & 0.635 & 0.661 \\
\hline \multirow{5}{*}{$I T U$} & \multicolumn{4}{|c|}{$" \mathrm{CR}=0.880 ; \mathrm{AVE}=0.648 "$} \\
\hline & ITU3 & Will utilize OB to do out bank transactions & 0.870 & 0.869 \\
\hline & ITU4 & Next time plan to utilize $\mathrm{OB}$ & 0.865 & 0.839 \\
\hline & ITU2 & Will frequently utilize $\mathrm{OB}$ in the future & 0.852 & 0.817 \\
\hline & ITU1 & Take OB for future usage & 0.787 & 0.684 \\
\hline
\end{tabular}


Table 2. Modeling results of structural equation

\begin{tabular}{|c|c|c|c|c|}
\hline $\mathbf{H}$ & Paths & Estimate & p-value & Result \\
\hline$H l_{a}$ & RIS- PRR & 0.863 & $* * *$ & Accepted \\
$H l_{b}$ & RIS- SER & 0.788 & $* * *$ & Accepted \\
$H l_{c}$ & RIS- SOR & 0.556 & $* * *$ & Accepted \\
$H l_{d-e}$ & RIS-F-PR & 0.606 & $* * *$ & Accepted \\
$H l_{f}$ & RIS- TIR & 0.486 & 0.028 & Accepted \\
\hline$H 2$ ITU & RIS & -0.228 & & Accepted \\
\hline
\end{tabular}

H1': "A second dimension of five risks - privacy risk, security risk, social risks, time risk and financial performance risk is seen as a risk".

H1d-e: Financial risk linked favorably to perceived risk.

Therefore, a revised model scale includes five first order dimensions following the analysis of the exploratory factor: risk of privacy, security risk, social risk, time risk and financial risk, known as the perceived risk-induced variable and the first-order-intensive risk-induced variable.

\section{2) Confirmatory Factor Analysis}

First-order - the first CFA, with a CFA loading factor less than 0.50 is removed after three indications - SER, FIR1, PER2. The second CFA shows the following 19 elements in its measuring model: "Chi-square (Translation 2) $\left(\chi^{2}\right) / \mathrm{dF}=1.572$; CFI $=0.945$; TLI $=0.933$; RMSEA $=.050(\mathrm{P}=0.000)$. Then the measuring model is data compatible". All CFA loading indices vary from 0.612 and $0.869(>0.5)$. The AVE accounts for 0.502 to $0.748(>0.50)$ of the average variance retrieved (Table I). The measurements are discriminating, because the AVE is higher than the respective square correlation coefficients (r2), thus achieving the scales. The measurements are thus qualified - the model has discrimination.

Second-order - The reflective second order factor CFA calculates relative Risk in the five risk categories of the display models - privacy hazards, security, social, transitory, and financial concerns: " $\chi^{2} / \mathrm{d}=0.933$; TLI $=0.945 ;$ RMSEA $=0.050(\mathrm{p}=0.000)$ ", This indicates the model meets data extremely well. CFA calculates relative risk to measurement models of the measurement items with perceived risk: H1' is thus supported Hypothesis.

\section{Modeling of structural equation}

Maximum likelihood (ML) estimations were carried out in the SEM (structural equation modeling). This model shows: "TLI $=0,934$; RMSEA $=0.050(\mathrm{p}=0,000)$," therefore the model shows acceptable adaptabilities. The model theory displays: TLI $=0.934$. Table II details the SEM findings.

Of course, it was noted that the coefficients of $\beta$ were $0,861, \quad 0.786,0,554,0,604$ and $€ 0.484 \quad(p<0,001)$ correspondingly, "with PRR, SER, SOR, F-PR and TIR. The analytical findings show that the risks perceived are considerably affected in all five areas - privacy risk, safety risk, social risk, time risks and financial performance risk. The H1a, H1b, H1c, H1d-e and H1f theories will thus be supported. Furthermore, RIS has a negative impact on ITU, where $\mu$ is $-0.226(p=0.028)$ and this is confirmed by $\mathrm{H} 2$ in turn. All assumptions have been demonstrated by the findings of the analysis". Figure 1 generally illustrates the perceived risk model of online banking purposes, including the model structure.

\section{Result Discussions}

The analysis results revealed that the risk perceived reflects the second order of dangers in five prime order variables: privacy risk, security risk, social risk, time-related risks and financial performance risk. This research added to Bauer, R.A. [8] perceived risk theory via a perceived risk factor and was compared to previous relevant studies, such as Chen C.S. [10], Featherman \& Pavlou [18], Littler \& Melanthiou [29]; Aldás-Manzano et al., [5]. 


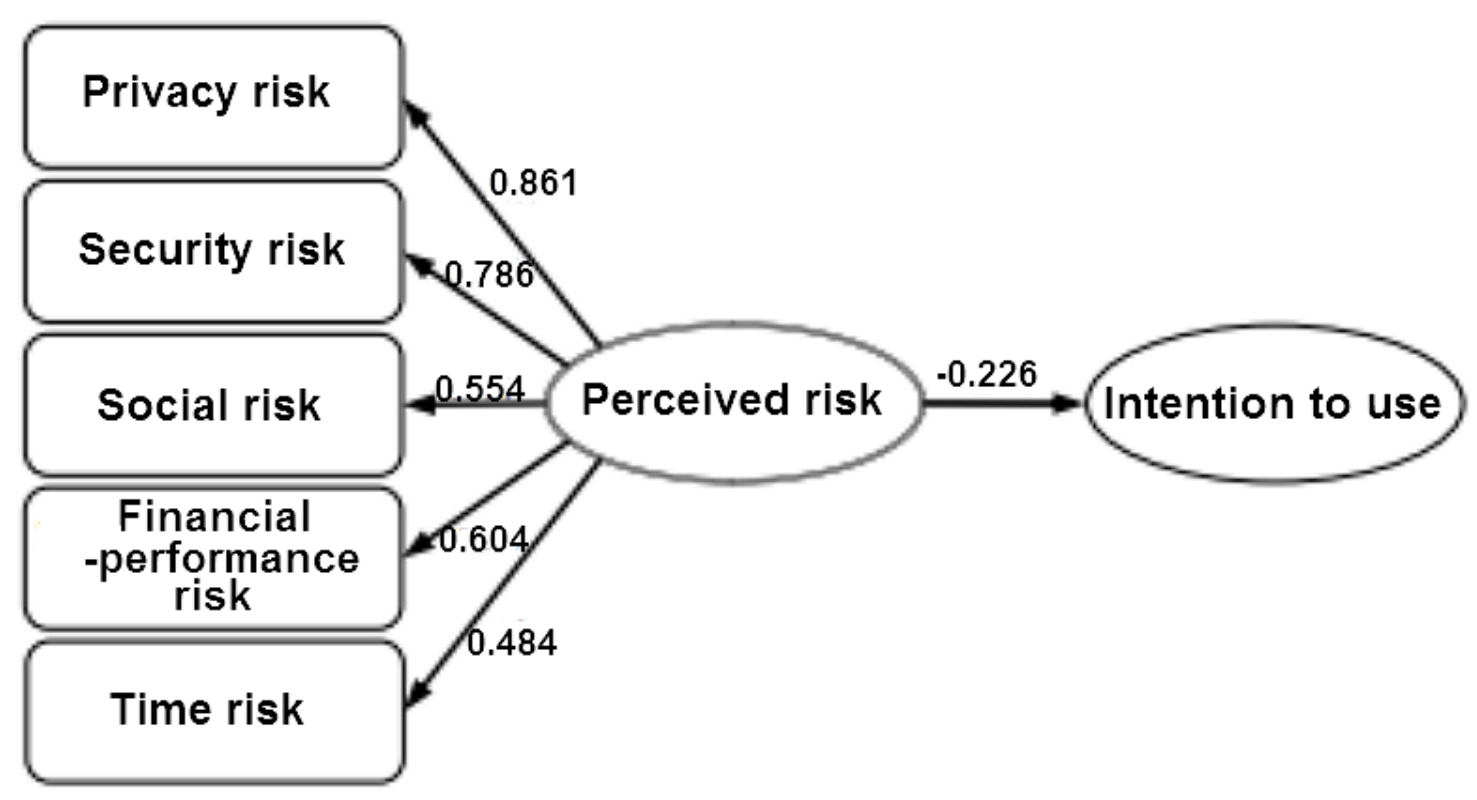

Figure 1. Risk perceived for online banking purposes

"Adjusted model The SEM findings showed the greatest connection between the risk factors in terms of privacy and perceived risk $(\mu=0,861)$, followed by the risk for security $(\mu=0,786)$, the risk of financial performance $(0,604)$, the social risk $(0,554)$ and the risk of time $(0.484)$ '". In addition, the perceived danger had an intentional impact $(\mu=0.226)$. Although this result is minor in comparison with Chen C.S. [10], in the connection between online banking intention and perceived risk, $\alpha$ is estimated to be -0.590 and -0.252 for two instances of regular and unusual users. Nonetheless, these findings have a higher impact on the intention for using online banks of a perceptive risk dimension than the research by Featherman and Paulov [18], "Aldás-Manzano et al., [5] or Martins et al. [31] ( in $\mu$ are $-0,146,-0,200$ and $-0,22010$ respectively".

This research adds to the perceived risk theory that reflects the second order, models and decomposes it into first order components - "privacy risk, security risk, social risk, time risk and financial performance risk". Another reason why the study results explain the relatively accomplished function of perceived risk in India's desire to use online banking - This adds to the link between other variables and online banking purpose and the whole theory of IT adoption. Furthermore, the study results offer management data for the Indian banks in their strategy.

\section{Conclusions}

The results of the study revealed that all measurements of the first and second order variables were recognized as an independent variable, and the desire to utilize them as a dependent variable that stabilizes confidence was termed a first order factor. Five "primary variables, including privacy risk, security risk, social risk, risk in time and purpose of usage", are given by the EFA (Exploratory Factor Analysis) retrieved under the suggested model. Two components of first order known as financial risk and performance risk are separated into one factor and a new term is suggested as financial risk. Therefore, seven original assumptions are downgraded. The first-order factors of the CFA and Second Order Reflective (CFA) demonstrate that measures are qualified - the model has a distinctive value. The SEM (Structural Equation Modeling) showed that a perceived risk (i.e., risk to privacy, risk of safety, social risk, and risk of time and financial performance) component has been modeled and broken down into components of first order as a composite variable. The perceived risk affects internet banking intention. Of course, 7 out of seven theories presented are accepted. The results of this research also show that the perceived risk plays a relatively high influence in using internet banking in India.

Although this research found how essential it was for the intention to utilize online banking that the perceived risk effect, certain limitations remain in the study. In future, a bigger sample will be acquired, the study scope will be expanded and measurements will be adjusted to take into account developments in India and globally. It also must include additional dimensions to IT adoption, including demographic factors in the model, and not just perceive the danger or desire to use as a study.

\section{REFERENCES}

[1] Ackerman, Mark \& Cranor, Lorrie \& Reagle, Joseph., "Privacy in e-commerce: examining user scenarios and privacy preferences," The 1st ACM conference on 
Electronic commerce (EC '99), Association for Computing Machinery, New York, NY, USA, 1-8, 1999. https://doi.org/10.1145/336992.336995.

[2] Ajzen, I., "From intention to actions: A theory of planned behavior," In J. Kuhl, \& J. Beckman (Eds.), Action control: From cognition to behavior, New York: Springer-Verlag pp. 11-39, 1985.

[3] Ajzen, I., "The theory of planned behavior," Organizational behavior and human decision processes, 50(2), 179-211, 1991. https://doi.org/10.1016/0749-5978(91)90020-T.

[4] Aladwani A.M., "Online banking: A field study of drivers, development challenges, and expectations," Int. J. of Inform. Manage., vol. 21 (3), pp. 213-225, 2001. DOI:10.1016/S0268-4012(01)00011-1.

[5] Aldás-Manzano, J., Lassala-Navarré, C., Ruiz-Mafé, C. and Sanz-Blas, S.), "Key drivers of internet banking services use", Online Information Review, Vol. 33 No. 4 , pp. 672-695, 2009.

https://doi.org/10.1108/14684520910985675

[6] Al-Jabri, I. M., "The intention to use mobile banking: Further evidence from Saudi Arabia," South African Journal of Business Management, ISSN 2078-5976, African Online Scientific Information Systems (AOSIS), Cape Town, Vol. 46, Iss. 1, pp. 23-34, 2015. http://dx.doi.org/10.4102/sajbm.v46i1.80.

[7] Barros, Lucia \& Botelho, Delane., "Hope, Perceived Financial Risk and Propensity for Indebtedness", BAR Brazilian Administration Review, 9, 454-474, 2012. https:// 10.1590/S1807-76922012000400006.

[8] Bauer, R.A., "Consumer Behavior as Risk-Taking, Dynamic Marketing for Changing World," American Marketing Association, Chicago, 389, 1960.

[9] Byrne, B.M., "Structural Equation Modeling With AMOS: Basic Concepts, Applications, and Programming," Third Edition (3rd ed.) Routledge 2016. https://doi.org/10.4324/9 781315757421

[10] Chen, ChauShen. "Perceived risk, usage frequency of mobile banking services," Managing Service Quality: An International Journal vol. 23 (5), pp. 410-436, 2013.

[11] Compeau, Deborah R., and Christopher A. Higgins., "Computer Self-Efficacy: Development of a Measure and Initial Test," MIS Quarterly 19, no. 2 (1995): 189-211. https://doi.org/10.2307/249688.

[12] Dada, Abimbola. "Adoption and Acceptance of Online Banking: A Comparative Study of UK and Nigeria Retail Banks." In Promotional Strategies and New Service Opportunities in Emerging Economies. edited by Nadda, Vipin and Sumesh Dadwal, and Roya Rahimi, 263-293. Hershey, PA: IGI Global, 2017. http://doi:10.4018/978-1-5 225-2206-5.ch012

[13] Davis, F et al, "Extrinsic and intrinsic motivation to use computers in the workplace," J. of Appl. Social Psychol., vol. 22 (14), pp. 1111- 1132, 1992

[14] Davis, F., "Perceived usefulness, perceived ease of use, and user acceptance of information technology," MIS Quart., vol. 13 (3), pp. 319-340, 1989.

[15] Dowling, Grahame R., "Perceived risk: the concept and its measurement," Psychology \& Marketing 3, no. 3 1986: 193-210 https://doi.org/10.1002/mar.4220030307.

[16] Durkin, Mark \& Jennings, Deirdre \& Mulholland, Gwyneth \& Worthington, Stephen., "Key influencers and inhibitors on adoption of the Internet for banking," Journal of Retailing and Consumer Services 15, pp. 348-357, 2008. DOI: 10.1016/j.jretconser.2007.08.002.

[17] Ezeoha A.E., "Regulating internet banking in Nigeria: Problems and Challenges - Part 1," Journal of Internet Banking and Commerce, Vol. 10, no.3. 2005

[18] Featherman, Mauricio S., and Paul A. Pavlou. "Predicting e-services adoption: a perceived risk facets perspective." International journal of human-computer studies 59 , no. 4 , pp.451-474, 2003.

[19] Fishbein, M., \& Ajzen, I., "Belief, Attitude, Intention, and Behavior: An Introduction to Theory and Research," Reading, MA: Addison-Wesley, 1975.

[20] Forsythe S.M. and Shi B., "Consumer patronage and risk perceptions in Internet shopping," Journal of Business Research 56 pp 867-875, 2003. doi:10.1016/S0148-2963(0 1)00273-9.

[21] Hair, Joseph F., "Multivariate Data Analysis", 7 th ed. London: Pearson, 2014.

[22] Halvadia, Nirav \& Patel, Vipul., "Study of Online Trust and Perceived Risk on Attitude towards Internet Banking Usage in India”, International Conference of Nirma Institute of Management, Ahmedabad, India, 2014 Volume: 978-93-5097-411-7

[23] Hampton-Sosa, W., \& Koufaris, M. "The Effect of Web Site Perceptions on Initial Trust in the Owner Company", International Journal of Electronic Commerce, 10:1, 55-81, 2005, DOI: 10.1080/10864415.2005.11043965.

[24] Haque, Ahasanul \& Tarofder, Arun Kumar \& Rahman, Muhammad \& Raquib, Md., "Electronic transaction of internet banking and its perception of Malaysian online customers," African Journal of Business Management, Vol.3 (6), pp. 248-259, 2009.

[25] Kassim, Normalini Md, and T. Ramayah, "Perceived Risk Factors Influence on Intention to Continue Using Internet Banking among Malaysians," Global Business Review, 16, 2015. 393-414. https://doi.org/10.1177/097215091556992 8.

[26] Khan, Ikram Ullah \& Hameed, Zahid \& Khan, Safeer., "Understanding online banking adoption in a developing country: UTAUT2 with cultural moderators," J. of Global Inform. Manage., vol. 25 (1), pp. 43-65, 2017.doi: 10.4018/JGIM.2017010103

[27] Kolodinsky, J., Hogarth, J.M., \& Hilgert, M.A., "The adoption of electronic banking technologies by US consumers," International Journal of Bank Marketing, vol. 22 (4), pp. 238-259, 2004.

[28] Lee, Ming-Chi. Factors influencing the adoption of Internet banking: An integration of TAM and TPB with perceived risk and perceived benefit. Electronic Commerce Research and Applications. 8. 130-141, 2009. https://10.1016/j.elera p.2008.11.006.

[29] Littler, Dale \& Melanthiou, Demetris, "Consumer 
perceptions of risk and uncertainty and the implications for behaviour towards innovative retail services: The case of Internet Banking," Journal of Retailing and Consumer Services vol.13 pp.431-443, 2006.DOI:10.1016/j.jretconse

[30] Maditinos et al., "An examination of the critical factors affecting consumer acceptance of online banking: A focus on the dimensions of risk," Journal of Systems and Information Technology 15 (1): 97-116, 2013.

[31] Martins, Carolina \& Oliveira, Tiago \& Popovič, Aleš., "Understanding the Internet banking adoption: A unified theory of acceptance and use of technology and perceived risk application," International Journal of Information Management, vol.34(1), pp.1-13, 2014. DOI: 10.1016/j.ijinfomgt.2013.06.002.

[32] Namahoot, K.S. \& Laohavichien, T., "Assessing the intentions to use internet banking: The role of perceived risk and trust as mediating factors," International Journal of Bank Marketing, Vol. 36 No. 2, pp. 256-276, 2018. https://doi.org/10.1108/IJBM-11-2016-0159

[33] Nguyen, Thanh D. \& Cao, Thi., "Structural model for adoption and usage of e-banking in Vietnam," J. of Econ. Develop., vol. 220, pp. 116-135, 2014.

[34] Nguyen, Thanh D. \& Nguyen, Dung \& Cao, Thi., "Acceptance and Use of Information System: E-Learning Based on Cloud Computing in Vietnam," Lecture Notes in Computer Science, vol. 8407, pp 139-149, 2014. https://doi.org /10.1007/978-3-642-55032-4_14.

[35] Nguyen, Van \& Nguyen, Thanh D., "Perceived risk in the e-payment adoption via social network J. of Econ. Develop. vol. 27 (12), pp. 66- 81, 2016.

[36] Park et al., "Risk-focused e-commerce adoption model: A cross country study," J. of Global Inform. Technol. Manage., vol. 7 (2), pp. 6-30, 2004.

[37] Patel V. et al., "Study of Online Trust and Perceived Risk on Attitude towards Internet Banking Usage in India," Consumer Behaviour and Emerging Practices in Marketing, 2013. ISBN Number: 978-93-5097-447-6

[38] Pham, Long, Nhi Y.Cao et al., "Structural models for E-banking adoption in Vietnam," Int. J. of Enterprise Inform. Syst., vol. 9 (1), pp. 31-48, 2013.

[39] Pikkarainen T., et al., "Consumer acceptance of online banking: An extension of the technology acceptance model," Internet Res., vol. 14 (3), pp. 224-235, 2004.
[40] Rogers, Everett M, "Diffusion of Innovations," Washington D.C: Free, 1995.

[41] Roy S.K. et al., "Predicting Internet banking adoption in India: A perceived risk perspective," J. of Strategic Market., vol. 25 no. (5-6), pp. 418-438, 2017. DOI: 10.1080/0965254X.2016.1148771

[42] SBV, "Application and development of banking technology”, 2015. Available: https://www.sbv.gov.vn

[43] Sitkin S.B. and Pablo A.L., "Reconceptualizing the Determinants of Risk Behavior," Academy of Management Review, Vol.17, No.1, 1992. https://doi.org/10.5465/amr.1 992.4279564 .

[44] Tan, M., \& Teo, T. S., "Factors influencing the adoption of Internet banking," Journal of the Association for information Systems, 1(1), vol. 5, 2000.

[45] Taylor, Shirley, and Peter A. Todd. "Understanding Information Technology Usage: A Test of Competing Models." Information Systems Research 6, no. 2 (1995): 144-76. http://www.jstor.org/stable/23011007.

[46] Thompson, Ronald L., Christopher A. Higgins, and Jane M. Howell., "Personal computing: Toward a conceptual model of utilization. MIS Quart., vol. 15 (1), pp. 125-143, 1991.

[47] Venkatesh V et al., "Consumer acceptance and use of information technology: Extending the unified theory of acceptance and use of technology," MIS Quart., vol. 36 (1), pp. 157-178, 2012.

[48] Venkatesh V. et al., "User acceptance of information technology: Toward a unified view," MIS Quart., vol. 27, pp. 425-478, 2003.

[49] Westin, A. F., and Maurici Danielle, "E-commerce \& Privacy: What Net Users Want hackensack", NJ: Privacy \& American Business, 1998.

[50] Yang, Qing, Chuan Pang, Liu Liu, David C. Yen, and J. Michael Tarn, "Exploring consumer perceived risk and trust for online payments: An empirical study in China's younger generation," Comput. in Human Behavior, vol. 50, pp. 9-24, 2015

[51] Yousafzai, S. Y., Foxall, G. R., \& Pallister, J. G., "Explaining internet banking behavior: theory of reasoned action, theory of planned behavior, or technology acceptance model?," Journal of applied social psychology, 40(5), 1172-1202, 2010 